\title{
A rede social acadêmica researchgate como mecanismo de visibilidade e internacionalização da produção científica brasileira e portuguesa na área de Biblioteconomia e Ciência da Informação
}

Raimunda Araujo Ribeiro

\begin{abstract}
Professora Adjunta do Departamento de Biblioteconomia da Universidade Federal do Maranhão - UFMA. Graduada em Biblioteconomia pela UFMA. Especialista em Metodologia do Ensino Superior pela UFMA. Mestre em Ciência da Informação pela Universidade de Brasília - UnB. Doutoranda em Multimédia em Educação pela Universidade de Aveiro. Bolsista CAPES
\end{abstract}

Lídia Oliveira

Graduada Filosofia pela Universidade de Coimbra. Mestre em Tecnologia Educativa pela Universidade de Aveiro, em parceria com as Universidades de Valenciennes/França e Mons/Bélgica. Doutora em Ciências e Tecnologias da Comunicação pela Universidade de Aveiro onde é professora associada com agregação, no Departamento de Comunicação e Arte Investigadora no DigiMedia - Digital Media and Interaction Research Centre, Portugal. PósDoutora pelo CES - Centro de Estudos Sociais da Universidade de Coimbra-Portugal

Cassia Furtado

Doutora em Informação e Comunicação em Plataformas Digitais, pela Universidade de Aveiro e Universidade do Porto, em Portugal. Mestre em Ciência da Informação pela Universidade de Brasília. Graduada em Biblioteconomia e em Comunicação Social pela Universidade Federal do Maranhão. Professora Adjunto IV da Universidade Federal do Maranhão, Departamento de Biblioteconomia e Programa de Pós-Graduação

http://dx.doi.org/10.1590/1981-5344/2937

Este estudo analisa a problemática da comunicação no seio das comunidades científicas da área de 
Biblioteconomia e Ciência da Informação e como as redes sociais on-line se configuram como novos espaços de disponibilização da documentação científica e interação dos investigadores. O foco deste estudo é o contributo da presença on-line dos investigadores das áreas em análise para a promoção da visibilidade e internacionalização do trabalho académico desenvolvido. Realizou-se o levantamento da presença dos referidos investigadores na Rede Social

ResearchGate (http://www. ResearchGate.net), suas motivações e percepções acerca da importância dessa presença para a visibilidade e internacionalização do trabalho de pesquisa que realizam. As motivações que nos levaram a escolher como cenários de investigação essas comunidades científicas no contexto brasileiro e português, dentre vários aspectos, destaca-se, a identificação com a temática e o interesse em contribuir com a comunidade científica dessa área no contexto Brasil e Portugal, a partir dos resultados desta investigação, que sublinham indicadores e subsídios necessários para a discussão nessa área, centrados nos seguintes eixos: internacionalização e visibilidade, tecnologias digitais e ensino superior e comunicação da ciência em rede. $A$ análise destes resultados permite gerar uma compreensão do papel desempenhado por estes novos espaços híbridos entre arquivo e espaço de interação, na dinâmica de comunicação da comunidade acadêmica e científica da área da Biblioteconomia e Ciência da Informação.

Palavras-chave: Comunicação em Ciência; Rede Social; Visibilidade; Internacionalização; Biblioteconomia; Ciência da Informação.

\section{The academic social network researchgate as a mechanism of visibility and internationalization of the brazilian and portuguese scientific production in the field of Library Science and Information Science}

This study analyzes the problem of the communication in the scientific communities from the Librarianship and Information Sciences areas and how online social 
networks are configured as new spaces for the availability of the scientific documentation and interaction of researchers. The focus of this study is the contribution of the online presence of researchers in the areas under analysis to promote the visibility and internationalization of the academic work developed. A survey of the presence of these researchers in the Social ResearchGate Network (http://www.ResearchGate.net), their motivations and perceptions about the importance of this presence for the visibility and internationalization of the research work carried out. The motivations that led us to choose as research scenarios these scientific communities in the Brazilian and Portuguese context, among various aspects, we highlight the identification with the theme, and the interest in contributing with the scientific community of this area in the context of Brazil and Portugal, from the results of this research which will highlight the indicators and the necessary subsidies for the discussion in this area, focusing on the following axes: internationalization and visibility, digital technologies and higher education and communication of the network science. The analysis of these results can generate an understanding of the role played by these new hybrid spaces between archive and space of interaction, in the dynamics of the communication from the academic and scientific community in the Librarianship and Information Science areas.

Keywords: Science communication; Social network; Visibility; Internationalisation; Library science; Information science.

Recebido em 27.09.2016 Aceito em 09.10.2017

\section{Introdução}

A Ciência da Informação (doravante CI) alicerçada no Paradigma Pós-Custodial Informacional e Científico, aliada a outras áreas do conhecimento (Biblioteconomia, Matemática, Comunicação, Tecnologia Computacional, dentre outras) vem crescendo, fortalecendo e contribuindo de maneira significativa para o progresso da ciência e da tecnologia, além de investigar os componentes relativos ao comportamento infocomunicacional, seus fluxos, meios e formas de otimizar o seu uso e acesso, de forma crítica e criativa (LIBÉRIO; MALHEIRO; ZAIDAN, 2011). 
Partindo desse pressuposto, pode-se inferir que a CI como disciplina é considerada uma

ciência social que investiga os problemas, temas e casos relacionados com o fenômeno [infocomunicacional] perceptível e cognoscível por meio da confirmação ou não das propriedades inerentes à gênese do fluxo, organização e comportamento infocomunicacionais (origem, coleta, organização, armazenamento, recuperação, interpretação, transmissão, transformação e utilização da informação) (SILVA, 2006, p. 140 -141).

Dentre as áreas investigadas pela Biblioteconomia e $\mathrm{CI}$, a comunicação da ciência se caracteriza por sua transversalidade, ao envolver vários atores sociais responsáveis por todo o processo de geração, produção, organização e divulgação da ciência, como: agências de fomento às pesquisas, bibliotecas, centros de documentação e informação, editoras e os investigadores, no Brasil e em Portugal (sujeitos desta investigação), ou em qualquer outro país (GOMES, 2013, p. 2).

Assim, a comunicação da ciência, por meio dos seus fluxos, sistemas e processos, acopla:

- A pesquisa - quando da elaboração de uma investigação, por meio da comunicação entre pares, em todas as esferas;

- O Sistema, quanto potencializa o fluxo contínuo de informações, entre editoras, bibliotecas, agência de financiamentos, entre outros;

- A Sociedade - por meio da partilha do conhecimento científico, por vias da comunicação pública da ciência/ divulgação científica (GOMES, 2013, p. 2).

Desse modo, para que esse processo de comunicação da ciência ocorra, torna-se necessário a existência de qualificação acadêmica e científica ao longo da vida, com vista à formação de grupos de pesquisas constituídos por profissionais prontos a interagir em uma sociedade que exige que estes estejam adaptados às mudanças, bem como possam criar mudanças, para assim impulsionar e promover a cooperação, o diálogo intercultural entre o sistema e a sociedade. Diante dessa perspectiva, "a reinvindicação de uma profissão científica e socialmente dignificada passa, também, por uma atitude de rigor e de competência" (NÓVOA, 2002, p. 37).

O diálogo intercultural em ambientes científico e acadêmico potencia a produção de novos conhecimentos e consequentemente novas práticas educativas, mediadas pela formação de redes sociais acadêmicas, por meio do desenvolvimento de pesquisas sistematizadas entre pares no sistema científico global. Corroborando com Nóvoa (2002, p. 37), "ficam assim esboçados os contornos de uma nova profissionalidade docente, que concede aos professores um novo papel na tripla dimensão pedagógica, científica e institucional."

É diante dessa nova profissionalidade docente que as redes sociais acadêmicas e científicas possibilitam a visibilidade das pesquisas 
brasileiras e portuguesas, na área de Biblioteconomia e Ciência da Informação, contribuindo para a comunicação da ciência em cenário internacional, além de promover o reconhecimento dos pesquisadores, das universidades e das comunidades científicas. Potencia também a interação, a colaboração, a partilha de ideias, a produção de conhecimentos, entre instituições localizadas em diferentes países e regiões de maneira eficaz. Parte-se do princípio de que "o processo de comunicação é inerente às atividades científicas, e o contato entre profissionais torna-se indispensável para desencadear 0 fluxo da informação e do conhecimento" (ALCARÁ et al., 2009, p. 145).

Estudo como o de Bufrem, Gabriel Junior e Sorribas (2011, p. 4) realizado na área das redes de colaboração científica permite que se analisem aspectos relacionados à sua "dinâmica estrutural de relacionamento, caracterização e evolução estrutural das redes de coautoria, impacto das investigações científicas, grau de colaboração, padrões de produtividade e coautoria, análise de domínio e de produção científica" (BUFREM; GABRIEL JUNIOR; SORRIBAS, 2011, p. 4), promovendo assim parâmetros de avaliação do impacto das produções científicas e o grau de visibilidade dos pesquisadores no cenário nacional e internacional.

Esta investigação evidencia-se no estudo da Rede Acadêmica ResearchGate, com foco no contexto brasileiro e português, como espaço de disponibilização da documentação científica e interação entre docentes e investigadores da área de Biblioteconomia e Ciência da Informação, pertencentes a Instituições de Ensino Superior Brasileiras e Portuguesas (IES). O nosso interesse em estudar as potencialidades das redes sociais acadêmicas, em especial, a ResearchGate, surgiu por esta se apresentar na contemporaneidade como uma mídia de comunicação social eficaz e de fácil acesso, que possibilita a promoção de relações nas comunidades científicas em escala global, o compartilhamento de informação e o conhecimento entre pares na área de Biblioteconomia e Ciência da Informação, bem como a partilha de publicações, novidades, atualização de conhecimentos, discussão e expressão de opinião.

Dessa forma, apresenta-se a estrutura deste artigo o qual contém uma introdução que delimita a justificativa e os objetivos deste estudo. $\mathrm{Na}$ sequência, encontram-se o referencial teórico sobre redes sociais acadêmicas e seus aspectos conceituais, além do enfoque sobre o contributo acadêmico e científico desta na área de Biblioteconomia e Ciência da Informação. Em seguida, encontram-se os procedimentos metodológicos de investigação empregados, a análise e discussão dos resultados, as conclusões e a lista de referências utilizadas.

\section{Referencial teórico}

As Tecnologias de Informação e Comunicação (doravante TIC) como ferramentas de colaboração e partilha, em ambientes educacionais vinculados à pesquisa, possibilitam a criação de novos espaços para o 
diálogo e a troca de experiências, entre as comunidades acadêmicas e científicas, potenciando a sua visibilidade, a aproximação entre culturas e, oportunizando trabalho em parceria em âmbito internacional (BASTOS; OLIVEIRA, 2009; CHINCHILLA-RODRÍGUEZ; MOYA-ANEGÓN, 2015).

Observa-se que uma das características essenciais do conhecimento científico, no Ciberespaço, também denominado de "rede" é a partilha, que por meio da web 2.0, viabiliza e estimula a criação de "espaços de conhecimentos emergentes, abertos, contínuos, em fluxo, não lineares, se organizando de acordo com os objetivos ou os contextos, nos quais cada um ocupa uma posição singular e evolutiva" (LEVY, 1999, p. 157).

Os ambientes infocomunicacionais na contemporaneidade caracterizam-se como elementos que movem e impulsionam as ações e atuações dos profissionais e organizações. Esses ambientes são considerados estratégicos para a vantagem competitiva, em todas as esferas da sociedade, causando mudanças na forma de produção, disponibilização e compartilhamento de informações, uma vez que emanam de relações sociais onde, sujeitos e meios existem de forma independente, logo é resultante de um processo cognitivo e do construcionismo social (ARAÚJO, 2010; SILVA; SILVA, 2012).

Esses espaços de interação on-line, onde os sujeitos informacionais farão uso de social networking software, exigem novos tipos de comportamentos informacionais. Em se tratando de ambientes organizacionais de ensino e pesquisa, é necessário o desenvolvimento de competências e habilidades para o uso efetivo dos recursos on-line focado na literacia dos media e na literacia informacional (SILVA; SILVA, 2012). Literacia aqui entendida como um processo educacional contínuo e em permanente evolução, responsável pelo desenvolvimento de competências comunicativas, interpretativas e culturais, sociais, técnico-instrumentais, capazes de desenvolver nos indivíduos "o pensamento crítico e a capacidade de resolver problemas" (VIEIRA; VIEIRA, 2008, p. 195).

O pensamento crítico e a capacidade reflexiva são os elementos que norteiam as relações na Rede. Pois exigem para além de capacidades técnicas e tecnológicas, ações responsáveis e éticas dos sujeitos informacionais no acesso, uso e partilha de conteúdo. Estas relações são constituídas por três elementos básicos: atores, vínculos ou relações e fluxos. A partir daí são constituídos os tipos de Online Social Networks, de acordo com os interesses sociais, educacionais, culturais ou profissionais dos indivíduos (SILVA; SILVA, 2012).

Portanto, a criação desses espaços on-line é facilitada pelas ferramentas disponibilizadas pela web 2.0, que possibilitam a criação e edição de ambientes on-line de forma mais fácil e rápida. Os servidores web são de hospedagem gratuita de conteúdos, bem como o número de ferramentas e possibilidades são ilimitadas (DOLELAN, 2015). Essas ferramentas propiciam a criação de redes sociais on-line que consistem em sistemas que conectam atores, a fim de viabilizar a comunicação e a criação de conexões constituídas por interações/relações e laços sociais (RECUERO, 2009, p. 24). 
Entretanto, nas redes sociais on-line, a interação ocorre com frequência entre atores que possuem interesses em comum, com a tendência para o crescimento instantâneo, pois quem está em rede sente a necessidade básica de explorar, conhecer e/ou contactar cada vez mais pessoas. Portanto, a rede social acadêmica pode ser definida como serviços baseados na web 2.0 que permitem aos indivíduos construir um perfil público ou semi-público dentro de um sistema limitado, articular uma lista de outros usuários com quem compartilham uma conexão, bem como visitar e percorrer listas de conexões com objetivos diversos em outros sistemas. Sendo assim, existem várias nomenclaturas e tipologias de redes sociais acadêmicas que podem variar de local para local, como exemplo cita-se a ResearchGate, foco deste estudo (ALMOUSA, 2011; MOLINA; MUNÕZ; DOMENECH, 2002).

Para Castells (1999), uma rede é um conjunto de nós interconectados que se articulam formando a espinha dorsal da sociedade que, por sua vez é formada por um conjunto de atores sociais ligados uns aos outros por meio de relações sociais, que podem ser representados pela teoria matemática - representada por grafos - através de pontos ou nós, que são atores, e linhas que refletem os laços e conexões.

Corroborando com os estudos de Castells (2009), Molina, Munõz e Domenech (2002), Tomael e Marteleto (2006) ${ }^{1}$ citado por Ferreira (2011) consideram uma rede como um conjunto de nós, com ligações entre si, denominadas de conexões e, uma rede social como um grupo de pessoas, organizações ou outros tipos de entidades sociais que se conectam por meio de relações sociais, incentivadas por amizade, relações de trabalho ou por compartilhamento de informações/conhecimentos, por meio de ligações que vão organizando e reorganizando a estrutura social.

Diante dos conceitos apresentados, pode-se inferir que redes/redes sociais são elementos formadores de nós, pelos quais são constituídas e efetivadas as relações sociais em ambientes diversificados, sejam estes profissionais ou culturais. Esses ambientes antes formados em espaços reais, atualmente com o boom das TIC, em especial da internet, passaram a ser formados em espaços on-line. Dentre esses espaços tem-se as redes sociais acadêmicas on-line como a Academia.edu e a ResearchGate, esta última universo deste estudo, considerada na atualidade como um mecanismo essencial que impulsiona as parcerias nos meios acadêmicos e científicos, indispensáveis ao desenvolvimento da ciência e tecnologia.

A ResearchGate foi fundada em 2008, e nesse mesmo ano já contava com 10.000 usuários. Dados da própria Rede demonstram que em 21 de outubro de 2015 já contava com 9 milhões de usuários. Em fevereiro de 2016, seus relatórios apontam que essa Rede conta com uma coleção formada por 81 milhões de publicações $(23,5 \%$ em texto completo), 193 países membros e 52 pesquisadores com prêmio Nobel

1 TOMAÉL, M. I.; MARTELETTO, R. M. Redes sociais: posições dos atores no fluxo da informação. Enc. Bíbli: $R$. Eletr. Biblioteconomias. CI. Info., Florianópolis, n.esp., $1^{0}$ sem. 2006. Disponível em: <https://periodicos.ufsc.br/index.php/eb/article/view/1518-2924.2006v11nesp1p75>. Acesso em: 30 jun. 2015. 
atribuído. A ResearchGate hoje está entre os maiores bancos de dados bibliográficos do mundo, embora não ultrapassando os números da Google Scholar (Tabela 1). O seu sucesso se assemelha a de outras Redes como a Academia.edu (ORDUÑA-MALEA; MARTÍN-MARTÍN; LÓPEZ-CÓZAR, 2016).

Tabela 1 - Quantitativo de documentos existentes nas principais bases de dados bibliográficos do mundo (março de 2016)

\begin{tabular}{l|l}
\multicolumn{1}{c|}{ Bases de dados } & \multicolumn{1}{c}{ Número de documentos } \\
\hline \hline Google Scholar (dados de junho de 2014) & 170.000 .000 (dados aproximados) \\
\hline Web of Science (todas as bases de dados) & 167.127 .889 \\
\hline ResearchGate & 81.000 .000 (dados aproximados) \\
\hline Microsoft Academic Search & 80.000 .000 (dados aproximados) \\
\hline Web of Science Core Collection & 61.856 .513 \\
\hline Scopus & 61.583 .942 \\
\hline Mendeley & 32.000 .00 \\
\hline Academia.edu & 10.767 .769 \\
\hline
\end{tabular}

Fonte: ORDUÑA-MALEA; MARTÍN-MARTÍN; LÓPEZ-CÓZAR (2016).

Os resultados apresentados na Tabela 1, demostram que a web é uma plataforma que expande as práticas de socialização do conhecimento. Os perfis dos cientistas nas redes sociais acadêmicas possibilitam estabelecer pontos de disseminação da sua produção para e entre seus pares, fornecendo uma variedade de opções para a divulgação dos conhecimentos gerados. Essas Plataformas, a exemplo das apresentadas na Tabela 1, criaram uma nova forma de fazer ciência. Assim, a prática da ciência é uma prática de comunicação, um ato de divulgação do conhecimento para um conjunto de pares. O conhecimento científico é disseminado por meio da publicação científica em revistas, anais de conferências e livros, disponibilizados também atualmente de forma mais intensiva em Plataformas como a ResearchGate, considerada como uma local chave para os cientistas que querem se envolver em discussões colaborativas, revisão por pares e compartilhamento de resultados. Consequentemente, isso dá um novo valor à produção de conhecimento na ciência, assim como lança luz sobre desempenho dos cientistas e, dos seus produtos científicos gerados. (ORDUÑA-MALEA; MARTÍN-MARTÍN; LÓPEZ-CÓZAR, 2016; BIRKHOLZ et al., 2013; VAN-NOORDEN, 2014).

Como se pode ver nos resultados do inquérito publicado na Revista Nature, em 2014, a ResearchGate é utilizada para dinâmicas cognitivas e sociais no âmbito da comunidade científica (Figura 1). 
Figura 1 - Motivação para uso das mídias sociais pelos acadêmicos/investigadores

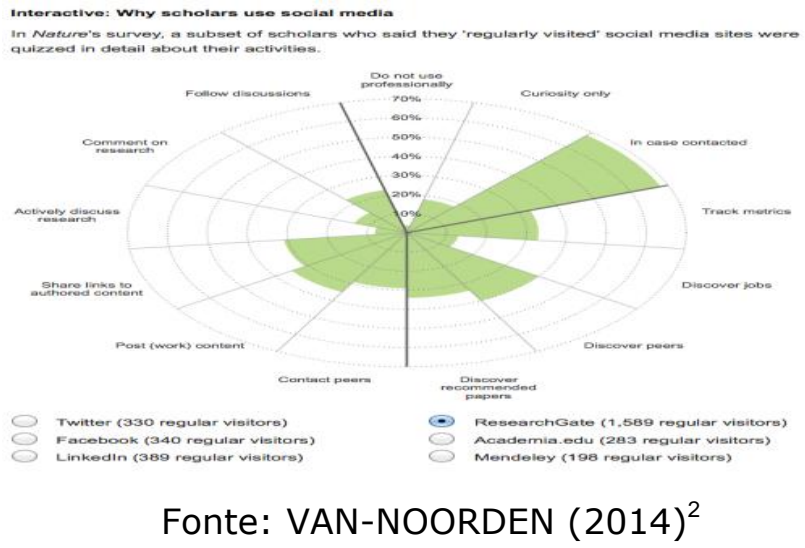

Em outra pesquisa de caráter global multilíngue envolvendo pesquisadores em todas as disciplinas, estágios de carreira e países, realizada pelos: Bibliotecário e Bibliotecária Bosman e Kramer (2015) da Biblioteca da Universidade de Utrecht, intitulada: 101 Innovations in Scholarly Communication: How researchers are getting to grip with the myriad of new tools, apresenta as mudanças ocorridas nos últimos anos nos processos da comunicação científica com o boom das ferramentas tecnológicas em ambientes de trabalho e, pesquisa nos espaços acadêmicos por pesquisadores. Nesse estudo, estes apresentam como questões de investigação: como os pesquisadores estão incorporando essas ferramentas em seus fluxos de trabalho de pesquisa? Quais as suas escolhas e por quê? Os resultados dessa pesquisa trarão uma contribuição valiosa para as bibliotecas, para os processos de investigação, para os financiadores e, também para os próprios pesquisadores.

Esse mesmo estudo aponta que metade das ferramentas que estão sendo investigadas por eles, que compõem o banco de dados de ferramentas de comunicação científica, foram criadas a partir de 2013 (Quadro 1). O número de crescimento dessas novas ferramentas parece até certo ponto refletir a relativa facilidade com que podem ser criadas ferramentas on-line. Seus criadores julgam importante construir ferramentas que suportem novas formas de trabalho, ou que repare falhas e omissões em ferramentas já existentes oferecidas pelos seus principais intervenientes (sejam editoras, empresas de tecnologia ou sociedades). 0 impulso para criação de novas ferramentas vem de financiadores (por exemplo, exigindo o arquivamento de dados do Open Access), mas também dos próprios pesquisadores que querem capitalizar sobre as possibilidades da internet em termos de colaboração. A finalidade principal desses atores é construir ferramentas propicias à recolha de dados, mineração, escrita, seleção revista, publicação e divulgação (KRAMER; BOSMAN, 2015).

2 Disponível em: <http://www.nature.com/news/online-collaboration-scientists-and-the-social-network-1.15711>. Acesso em: 4 abr. 2016. 
Quadro 1- Some tools created since 2013

\begin{tabular}{|l|l|}
\hline research activity & some tools created since $\mathbf{2 0 1 3}$ \\
\hline $\begin{array}{l}\text { experimenting and } \\
\text { collecting/mining data }\end{array}$ & ManyLabs, Liquid.io, Sample of Science, Crowdtruth \\
\hline writing & Authorea, Fiduswriter, RMarkdown, Shiny (RStudio) \\
\hline journal selection tools & JournalGuide, JournalReviewer, Journalysis, Scirev \\
\hline publishing & OLH, RIO, ScienceOpen, ProcPos, PaperNow \\
\hline outreach & Frontiers for Young Minds, DrawScience, Useful Science, SciWorthy \\
\hline
\end{tabular}

Fonte: KRAMER; BOSMAN (2015).

Essa pesquisa aponta para a necessidade da avaliação do impacto das ferramentas tecnológicas em ambientes de ensino e pesquisa, por parte de Bibliotecários e Cientistas da Informação, com o intuito de verificar se estão efetivamente colaborando para a melhoria dos fluxos de geração, produção e compartilhamento de informações/conhecimentos, essenciais na contemporaneidade, agilizando as atividades de investigação, mais especificamente a coleta de dados, as ferramentas de seleção de periódicos, o processo de publicação e a divulgação dos produtos científicos gerados, trazendo assim, retornos reais às necessidades das comunidades científicas envolvidas, independentemente da área de conhecimento que será beneficiada.

No caso da área da Biblioteconomia e CI, universo desta pesquisa, onde o foco está centrado na produção, organização, tratamento, divulgação e compartilhamento da informação, torna-se mais que necessária a adesão dos profissionais desta área ao uso de recursos tecnológicos que viabilizem o processo infocomunicacional entre pares, alargando as possibilidades de interação, compartilhamento e visibilidade dessas comunidades de profissionais, docentes e investigadores (BORGES, 2007; KRAMER; BOSMAN, 2015).

Essa adesão traz à tona uma mudança de comportamento, provocada pelo uso dessas ferramentas nas quais se incluem Facebook, Hi5, Linkedln, Twitter (sites de interesses profissionais e sociais), Ning e Academia.edu, Google Scholar e a ResearchGate (sites de interesses acadêmicos), YouTube, Flickr e SlideShare (sites de compartilhamento de mídia), sites de bookmarking social como delicious, Mendeley, Bibsonomy, Zotero e CiteUlike, (sites de partilha de referências) que possibilitam aos indivíduos a criação de uma identidade e um perfil profissional on-line, favorecendo a criação de uma presença on-line, nos mais variados ambientes sociais, acadêmicos e profissionais (DONELAN, 2015; MORAIS et al., 2014; THELWALL; KOUSHA, 2014).

Ambientes on-line têm o potencial para ajudar os cientistas a encontrar colaboradores apropriados de forma mais rápida e eficiente, além de possibilitar a divulgação dos resultados das suas investigações em tempo real. Esses ambientes também permitiram, ao longo das últimas décadas, à ciência tornar-se significativamente mais colaborativa, além de alterar de forma significativa as práticas atuais de acadêmicos e 
professores no ensino superior. Contribuem também para aumentar a comunicação científica, fortalecer as relações e, facilitar a colaboração em pesquisa, a publicação, refletindo sobre ideias, divulgação de informações e discussão de questões em um formato aberto público (THELWALL; KOUSHA, 2014, ALMOUSA, 2011; MANCA; RANIERI, 2016).

Para tanto, a dinâmica social da construção do debate acadêmico e científico on-line, por meio das redes sociais acadêmicas representa uma mais-valia na construção social da comunicação científica, na ressignificação do papel das comunidades científicas, e no processo de transformação da informação em conhecimento público e no fortalecimento do compromisso público com a ciência. Este novo estilo de comunicação institucionaliza o perfil profissional online, marca a presença online do docente/investigador na rede, aumentando as oportunidades e diversificando as suas formas de atualização profissional. Tal processo cria uma demanda institucional que fortalece a rede de conexões e a representatividade das comunidades científicas no sistema de comunicação científica global. Além de suportar um processo distribuído de rede de construção de conhecimentos, por meio da conexão e da promoção de redes de interação social (PINHEIRO; RIBEIRO, 2005; MANCA; RANIERI, 2016).

Destarte, há de se considerar que as mudanças advindas da implementação das TIC, em todos os segmentos na sociedade da informação mudaram de forma definitiva a maneira como as comunidades científicas em rede geram e partilham conhecimento, bem como estas se tornam visíveis e adquirem prestígio profissional, institucional e científico entre pares em escala global. Em especial, as redes acadêmicas proporcionam processos comunicativos inovadores entre pares, possibilitando a discussão de dados negativos, que jamais poderiam ser publicados de outra forma, assim como a revisão de pares por artigos e o upload de dados brutos. Todas essas inovações possibilitam a criação de elos que potenciam de forma direta ambientes cooperativos essenciais para a construção de uma ciência pública fortalecida por elos que objetivam o bem comum e compartilhado (ORDUÑA-MALEA; MARTÍNMARTÍN; LÓPEZ-CÓZAR, 2016).

\section{Procedimentos metodológicos}

Esta investigação tem como foco central avaliar a problemática da comunicação no seio das comunidades científicas brasileiras e portuguesas da área de CI e da Biblioteconomia, destacando como as redes sociais online se configuram como espaços de disponibilização da comunicação científica e interação entre docentes e investigadores para a promoção da visibilidade e internacionalização do trabalho desenvolvido nessa área.

A investigação empírica foca-se no uso da rede social Researchgate:

La red social académica ResearchGate ofrece a los usuários un amplio catálogo de indicadores tanto de impacto científico (citas) como de uso (lecturas, descargas) de documentos, así como una 
serie de indicadores combinados derivados de la actividad realizada por los usuarios en la plataforma. [...] ResearchGate ofrece servicios y datos de inestimable valor para los investigadores: permite depositar y tipificar una amplia diversidad de materiales académicos (incluso registrar de forma gratuita DOIs para éstos), conocer el interés del sector profesional y docente en ciertos materiales (presentaciones, cursos, etc.), conocer las personas e instituciones interesadas en tu trabajo, obtener datos de citas cada vez más completos según crece la cobertura de la plataforma (nada desdeñable en ciertas disciplinas como biomedicina), y fomentar la colaboración y networking académico. (ORDUÑA-MALEA; MARTÍNMARTÍN; LÓPEZ-CÓZAR, 2016, p. 309).

A análise das redes sociais parte de duas vertentes básicas, a primeira cujo foco centra-se em redes inteiras (whole networks) e a segunda em redes personalizadas (ego-centered networks). Essa análise tem como ponto de partida a relação estrutural da rede ou grupo social. As redes são aqui entendidas como assinaturas de identidade social, ou seja, o padrão estabelecido nas relações entre indivíduos e a forma como estes estão mapeando as suas preferências e características com seus pares participantes da rede. O outro ponto de análise centra-se no papel das pessoas, ou seja, como estas estão sendo compreendidas pelos grupos (redes) a que são pertencentes, bem como por meio das posições que possuem dentro dessas redes. O diferencial de análise dos dois pontos está no corpus selecionado pelo investigador (RECUERO, 2004).

Partindo desse princípio, a análise estrutural das redes sociais tem como objetivo o estudo da interação como princípio fundamental para o estabelecimento das relações sociais entre indivíduos, por meio dos quais se originarão as redes sociais, tanto no mundo real, quanto no mundo virtual. Pois, em uma rede social, os sujeitos são os nós e as arestas são formadas pelos laços sociais oriundos das interações sociais. Na contemporaneidade, as análises das redes sociais on-line, em especial as redes sociais acadêmicas, são fundamentais para que se possa compreender como estão sendo estabelecidos as conexões e os laços entre pares nas comunidades científicas em escala nacional e internacional, qual o nível dessas relações que estão sendo construídas, como estão sendo estabelecidas as parcerias para formação de grupos de pesquisas em nível de instituições de ensino superior ou instituições de fomento a pesquisas, para fins de partilha, produção e divulgação da produção científica gerada (RECUERO, 2004; YANG; LESKOVEC, 2015; VAN-NORDEN, 2014; NICHOLAS et al., 2015).

Para tanto, traçou-se como objetivos: levantar a presença dos docentes e investigadores da área de Biblioteconomia e CI na Researchgate, identificar as suas motivações para terem um perfil na Researchgate e avaliar as percepções dos docentes e investigadores acerca do contributo dessa rede social on-line para a presença, visibilidade e internacionalização dos trabalhos e pesquisas desenvolvidas. 
De acordo com os objetivos delineados, optou-se pelo estudo de caso descritivo - interpretativo como método de pesquisa, tendo em vista que este possibilitará o estudo pormenorizado e detalhado do caso selecionado, ou seja, a presença dos docentes e investigadores da área de Biblioteconomia e Ciência da Informação na ResearchGate, além do estabelecimento de significados com vistas a permitir o alcance dos objetivos traçados (STAKE, 2015).

Para Yin (2015) o estudo de caso possibilita a investigação de fenômenos contemporâneos, ou seja, no caso específico desta investigação torna possível que se avalie a presença desses investigadores na ReserchGate, bem como as suas motivações e percepções para possuírem um perfil nessa Rede. Para tanto, a base desta investigação centrar-se-á em estudar os processos de comunicação da ciência, dos docentes/investigadores dessas comunidades numa perspectiva holística e do mundo real, ou seja, em seus cenários de atuação profissional, onde desenvolvem as suas atividades científicas, considerando a complexidade sistêmica desses contextos.

Reconhece-se, que o "estudo de caso conta com múltiplas fontes de evidência, [ao] beneficiar-se do desenvolvimento anterior das proposições teóricas para orientar a coleta e análise de dados", pois este envolve "as técnicas de coleta de dados e as abordagens específicas à análise de dados" (YIN, 2015, p. 18).

Desse modo, para o desenvolvimento do processo investigativo, o pesquisador pode utilizar uma grande diversidade de técnicas de recolha de dados que pode ser determinado pelo quadro teórico utilizado e pelos objetivos delineados para o desenvolvimento de uma pesquisa (YIN, 2015) sendo, neste caso, utilizado o inquérito por questionário com questões abertas e fechadas. Para Martins (2006) o questionário, também denominado de survey (pesquisa ampla), consiste num dos procedimentos mais utilizados para se recolher informações.

Para tanto, foi elaborado um questionário para resposta on-line e disponibilizado no Google Forms, cuja divulgação esteve a cargo das investigadoras autoras deste artigo, sendo respondido entre os meses de junho a julho de 2015. O instrumento foi construído e afinado tendo em conta os objetivos previstos e posteriormente encaminhado o link via email aos docentes/investigadores vinculados a IES públicas e privadas brasileiras e portuguesas (Quadros 2, 3 e 4).

É interessante ressaltar que nesta investigação não se teve como exigência identificar quantos docentes/investigadores existem nas IES públicas e privadas da área de Biblioteconomia e Ciência da Informação no Brasil e em Portugal (Quadros 2, 3 e 4). Mas, sim considerou-se como prioritário para este estudo, atingir o máximo de Escolas dessas áreas pertencentes aos países investigados, para que se possa alcançar um retrato o mais fiel possível das reais motivações e percepções desses inquiridos sobre a contribuição da ReseachGate como Plataforma de comunicação indispensável na Sociedade da Informação a visibilidade e 
internacionalização das pesquisas desenvolvidas nessas comunidades científicas.

Assim sendo, procedeu-se a um levantamento sistemático da presença dos docentes e investigadores da área Biblioteconomia e Ciência da Informação na Rede acadêmica ResearchGate. Esse primeiro passo permitiu que se fizesse um mapeamento e uma quantificação da presença dos investigadores brasileiros e portugueses nessa Rede.

Com esse levantamento observou-se que de acordo com a rede de relações e interesses entre investigadores da área de Biblioteconomia e Ciência da Informação, foram localizados 27 docentes/ investigadores brasileiros, vinculados a Instituições de Ensino Superior (IES) públicas brasileiras e Institutos de Pesquisas, conforme demonstrados na Tabela 2.

Tabela 2 - Docentes/Investigadores brasileiros com perfil na ResearchGate

\begin{tabular}{l|l|l|l|l|l|l|l|l|l|l|l|l|l}
\hline $\begin{array}{c}\text { U. } \\
\text { Brasileiras }\end{array}$ & UnB & UFRJ & UFSCar & UFMG & UFBA & UEL & UERJ & UFAL & UFPb & UFF & IBICT & USP & Unesp \\
\hline \hline $\begin{array}{l}\text { Quant./ } \\
\text { Docentes }\end{array}$ & 08 & 03 & 02 & 03 & 01 & 02 & 01 & 01 & 01 & 01 & 02 & 02 & 01 \\
\hline
\end{tabular}

Fonte: Pesquisa realizada na Rede social acadêmica ResearchGate.

Em relação aos docentes e investigadores portugueses foram localizados 21, também vinculados a IES públicas e privadas portuguesas (Tabela 3).

Tabela 3 - Docentes/Investigadores portugueses com perfil na ResearchGate

\begin{tabular}{c|l|l|l|l|l|l|l|l}
\hline $\begin{array}{c}\text { U. } \\
\text { Portuguesas }\end{array}$ & $\begin{array}{c}\text { U. } \\
\text { Minho }\end{array}$ & $\begin{array}{c}\text { U. } \\
\text { Porto }\end{array}$ & $\begin{array}{c}\text { U. } \\
\text { Coimbra }\end{array}$ & $\begin{array}{c}\text { U. } \\
\text { Portucalen } \\
\text { se }\end{array}$ & I. P. Porto & $\begin{array}{c}\text { U. } \\
\text { Lisboa }\end{array}$ & $\begin{array}{c}\text { U. } \\
\text { Católica } \\
\text { Portuguesa }\end{array}$ & $\begin{array}{c}\text { U. } \\
\text { Fernando } \\
\text { Pessoa }\end{array}$ \\
\hline \hline Quant./Docentes & 07 & 06 & 02 & 01 & 02 & 02 & 01 & 01 \\
\hline
\end{tabular}

Fonte: Pesquisa realizada na Rede social acadêmica ResearchGate.

Com esta pesquisa, pode-se perceber que as linhas de interesse de investigação dessses docentes/investigadores centram-se nas áreas de: Ciência da Informação, Ciências da Comunicação, Comunicação Científica, Comunicação e Mídia, Bibliotecas digitais, Open Access, TIC, Mídia Social, Representação do conhecimento, dentre outras.

Foi realizado, também, um levantamento das Escolas de Biblioteconomia e Ciência da Informação brasileiras e portuguesas com cursos de graduação e pós-graduação, conforme Quadros 2, 3 e 4, às quais foram enviados, por e-mail a Coordenações, Departamentos e Direção dessas Escolas, o link do questionário, instrumento de recolha de dados desta investigação aos docentes/investigadores ligados a essas Instituições. 
A rede social acadêmica researchgate como mecanismo de visibilidade e internacionalização da produção científica brasileira e portuguesa na área de Biblioteconomia e Ciência da Informação
Raimunda Araujo Ribeiro; Lidia Oliveira; Cassia

Furtado

\section{Quadro 2 - Instituições de Ensino Superior com Programas de Pós-} graduação na área de Ciência da Informação e Biblioteconomia no Brasil

\begin{tabular}{l} 
INSTITUICÓES DE ENSINO SUPERIOR COM PROGRAMAS DE PÓS-GRADUACÁ̃O \\
EM BIBLIOTECONOMIA E CIÊNCIA DA INFORMAÇÃO NO BRASIL POR REGIÂOO \\
\hline CENTRO-OESTE
\end{tabular}

Programa de Pós-Graduação em Ciência da Informação (PPGCINF) - Universidade de Brasília (UnB) - Brasília

\section{NORDESTE}

Programa de Pós-Graduação em Ciência da Informação (PPGCI) - Universidade Federal
da Bahia (UFBA)

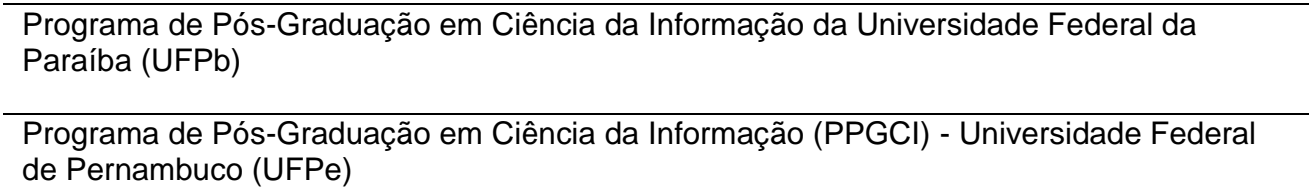

\section{SUDESTE}

Programa de Pós-Graduação em Ciência da Informação da IBICT/ UFRJ
Programa de Pós-Graduação em Biblioteconomia (PPGB) - Mestrado Profissional em Biblioteconomia /Universidade Federal do Estado do Rio de Janeiro (UNIRIO) - Rio de Janeiro - Brasil

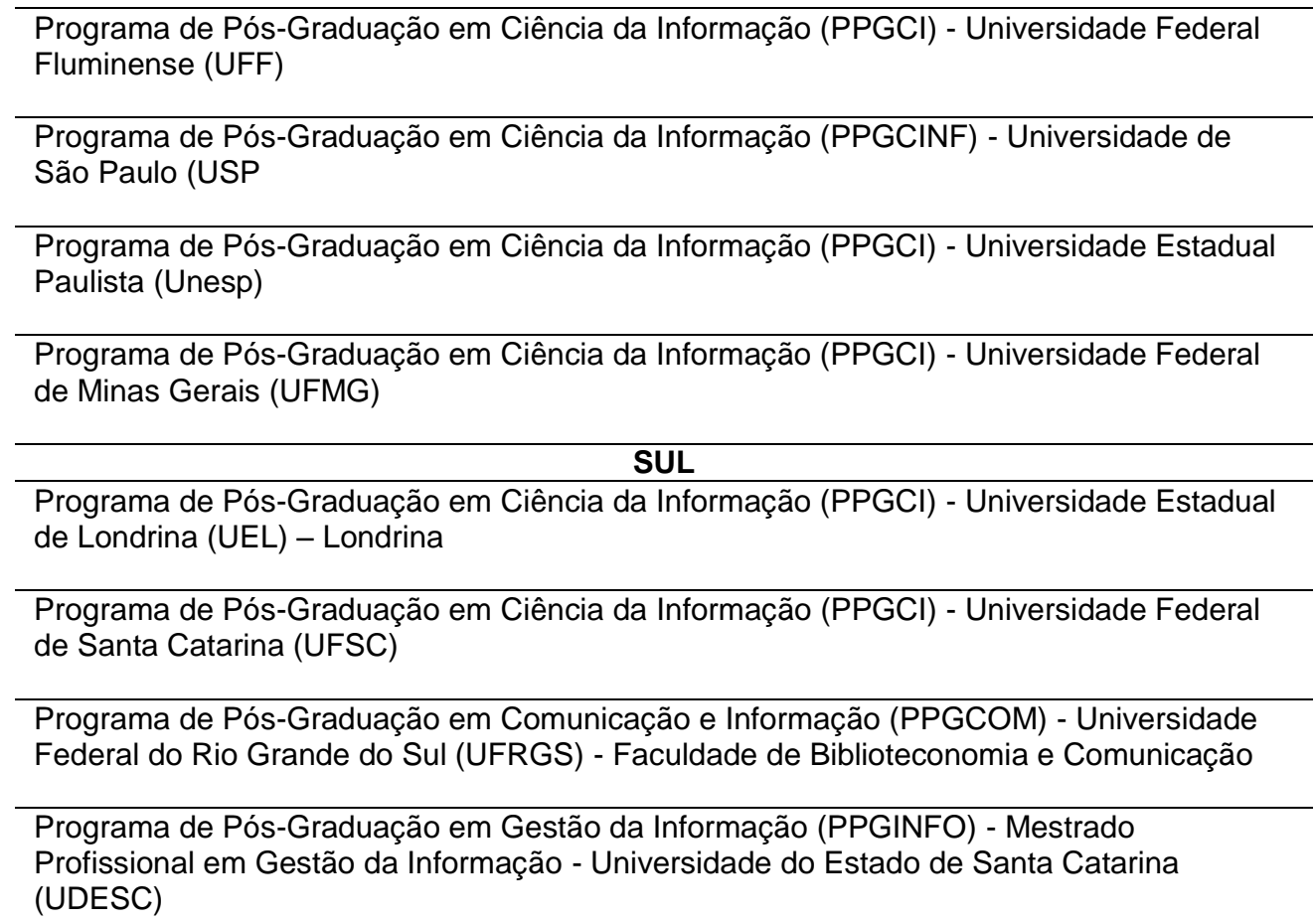

Fonte: Pesquisa realizada na Associação Brasileira de Educação em Ciência da Informação (2015). ${ }^{3}$

\footnotetext{
${ }^{3}$ ABECIN. 2015. Disponível em: <http://www.abecin.org.br/abecin conteudo.php?id=20>. Acesso em: 21 mar. 2015.
} 
A rede social acadêmica researchgate como mecanismo de visibilidade e internacionalização da produção científica brasileira e portuguesa na área de Biblioteconomia e Ciência da Informação
Raimunda Araujo Ribeiro; Lidia Oliveira; Cassia

Furtado

Quadro 3 - Instituições de Ensino Superior com Programas de Pósgraduação na área de Ciências da Documentação Informação e em Portugal

\title{
INSTITUIC̄̃ES DE ENSINO SUPERIOR COM PROGRAMAS DE PÓS-GRADUAÇÃO EM HISTÓRIA E PATRIMÔNIO, CIÊNCIA DA INFORMAÇÃO E DA DOCUMENTAÇÃO EM PORTUGAL
}

\begin{abstract}
Doutoramento em Informação e Comunicação em Plataformas Digitais - Universidade de
Aveiro, Departamento de Comunicação e Arte - Universidade do Porto, Faculdade de Letras (Aveiro e Porto - Portugal)

Mestrado em Ciências da Documentação e Informação- Universidade de Lisboa, Faculdade de Letras

Mestrado em História e Patrimônio - Arquivos Históricos, Universidade do Porto, Faculdade de Letras, Porto - Portugal
Mestrado em Ciência da Informação, Universidade do Porto, Faculdade de Engenharia e
Faculdade de Letras, Porto, Portugal

Fonte: Pesquisa realizada na Associação Portuguesa de Bibliotecários, Arquivistas e Documentação (BAD). ${ }^{4}$

\section{Quadro 4 - Escolas de Graduação em Biblioteconomia e Ciência da Informação Brasileiras}

\begin{tabular}{|c|}
\hline $\begin{array}{l}\text { INSTITUIÇÕES DE ENSINO SUPERIOR COM CURSOS DE } \\
\text { BIBLIOTECONOMIA NO BRASIL POR REGIÃO } \\
\end{array}$ \\
\hline CENTRO-OESTE \\
\hline Universidade de Brasília - UnB - Brasília - DF - Brasil \\
\hline $\begin{array}{l}\text { Instituto de Ensino Superior da Funlec - IESF - Campo Grande - MS - } \\
\text { Brasil }\end{array}$ \\
\hline NORDESTE \\
\hline Universidade Federal da Paraíba - UFPB - João Pessoa - PB - Brasil \\
\hline Universidade Federal de Alagoas - UFAL - Maceió - AL - Brasil \\
\hline Universidade Federal de Pernanbuco - UFPE - Recife - PE - Brasil \\
\hline Universidade Federal do Ceará - UFC - Fortaleza - Ceará - Brasil \\
\hline Universidade Federal do Cariri - UFCA - Juazeiro do Norte - CE - Brasil \\
\hline Universidade Federal da Bahia - UFBA - Salvador - BA - Brasil \\
\hline $\begin{array}{l}\text { Universidade Federal do Riop Grande do Norte - UFRN - Natal - RN - } \\
\text { Brasil }\end{array}$ \\
\hline NORTE \\
\hline Universidade Federal do Pará - UFPA - Belém - PA - Brasil \\
\hline SUDESTE \\
\hline $\begin{array}{l}\text { Faculdades Integradas Coração de Jesus - FAINC - Santo André - São } \\
\text { Paulo - SP - Brasil }\end{array}$ \\
\hline Universidade USP - São Paulo - SP - Brasil \\
\hline Universidade Federal de São Carlos - UFSCar - São Carlos - São P \\
\hline
\end{tabular}

\footnotetext{
${ }^{4}$ Disponível em: <http://www.apbad.pt/Formacao/formacao cdisp.htm>. Acesso em: 21 mar. 2015.
} 


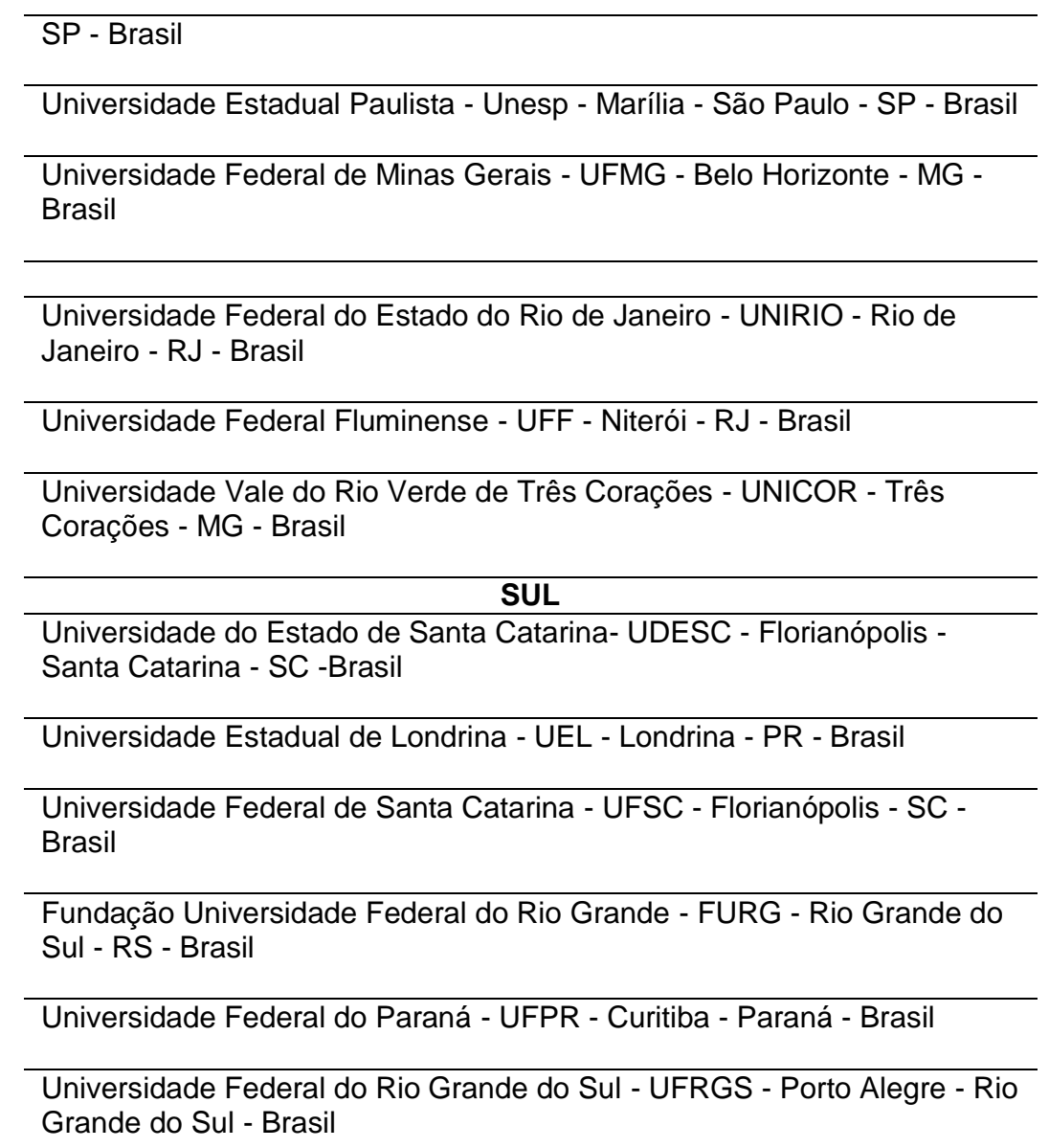

Fonte: Pesquisa realizada na Associação Brasileira de Educação em Ciência da Informação (2015).

Procedeu-se também ao envio do e-mail com o link do questionário aos docentes/investigadores da área de CI e Biblioteconomia brasileiros e portugueses localizados na Researchgate.

As secções seguintes apresentam a análise e discussão dos resultados e as conclusões, conforme os dados coletados e analisados.

\section{Análise e discussão dos resultados}

Dos questionários disponibilizados em plataforma on-line e links encaminhados via e-mail aos docentes e investigadores brasileiros e portugueses com perfil na Researchgate, bem como às Escolas de Biblioteconomia e Ciência da Informação vinculados a IES públicas e privadas brasileiras e portuguesas, teve-se o retorno de apenas 39 questionários. Destes, apenas 18/46,2 (Tabela 4), possuem perfil nessa Rede, foco da análise desta investigação.

A análise dos dados coletados para este estudo, no que refere às questões abertas será discutida em paralelo com as questões fechadas, apresentadas nas tabelas. As questões fechadas envolvem tratamento no editor de planilhas excel, ao nível de estatística descritiva básica, geradas, 
a partir do Google Forms. Estes dados foram agrupados para análise, em conformidade com as seguintes categorias:
a) Perfil dos participantes;
b) Perfil na ResearchGate;
c) Uso da ResearchGate;
d) Motivação para o uso da ResearchGat.

Constata-se na Tabela 4 que, em relação aos anos de atuação profissional, os docentes/investigadores, possuem entre 16 a 20 $(4 / 22,2 \%), 21$ a $25(4 / 22,2 \%), 26$ a $30(3 / 16,7 \%)$ e 6 a $10(3 / 16,7)$ anos de experiência docente. Quanto a idade, a maioria $10 / 55,6 \%$, possui entre 50 a 60 anos de idade e mais de 60 anos, enquanto que $8 / 44,4 \%$ apresenta entre 30 a 40 anos, e 40 a 50 anos. Em relação ao gênero $10 / 58,8 \%$, ou seja, a maioria, pertence ao gênero feminino e $7 / 41,2 \%$ ao gênero masculino. No que refere às modalidades de ensino, a maioria, ou seja, $16 / 88,9 \%$, leciona na modalidade presencial, os demais $3 / 16,7 \%$ na modalidade B-learning e 2/11,1\% E-learning. Em relação à instituição a que pertencem, os inquiridos brasileiros (9/50\%) e portugueses $(8 / 44,4 \%)$, são oriundos de IES.

Tabela 4 - Perfil dos participantes

\begin{tabular}{|c|c|c|c|c|c|c|c|c|c|c|c|c|c|c|}
\hline \multicolumn{3}{|c|}{$\begin{array}{c}\text { Anos/Experiência } \\
\text { docente } \\
\mathrm{N} \%\end{array}$} & \multicolumn{3}{|c|}{$\begin{array}{l}\text { Faixa etária } \\
\text { N\% }\end{array}$} & \multicolumn{3}{|c|}{$\begin{array}{l}\text { Gênero } \\
\text { N\% }\end{array}$} & \multicolumn{3}{|c|}{$\begin{array}{l}\text { Modalidade de Ensino } \\
\text { N\% }\end{array}$} & \multicolumn{3}{|c|}{$\begin{array}{c}\text { País a que pertence } \\
\mathrm{N} \%\end{array}$} \\
\hline $\begin{array}{l}\text { Até } 5 \\
\text { anos }\end{array}$ & 1 & 5,6 & $\begin{array}{c}\text { Até } 30 \\
\text { anos }\end{array}$ & 0 & 0 & $\bar{M}$ & 7 & 441,2 & Presencial & 16 & 88,9 & Brasil & 9 & 50 \\
\hline 6 a 10 & 3 & 16,7 & 30 a 40 & 4 & 22,2 & $F$ & 10 & 58,8 & E-learning & 2 & 11,1 & Portugal & 8 & 44,4 \\
\hline 16 a 20 & 4 & 22,2 & 40 a 50 & 4 & 22,2 & & & & B-learning & 3 & 16,7 & Outros & 1 & 5,6 \\
\hline 21 a 25 & 4 & 22,2 & 50 a 60 & 5 & 27,8 & & & & & & & & & \\
\hline 26 a 30 & 3 & 16,7 & $\begin{array}{l}\text { Mais } \\
\text { de } 60\end{array}$ & 5 & 27,8 & & & & & & & & & \\
\hline 31 a 35 & 0 & 0 & & & & & & & & & & & & \\
\hline $\begin{array}{l}\text { Mais de } \\
\quad 35\end{array}$ & 3 & 16,7 & & & & & & & & & & & & \\
\hline
\end{tabular}

Fonte: Dados da pesquisa.

Percebe-se com os dados apresentados na Tabela 4, que a maioria dos inquiridos leciona na modalidade presencial, o que leva a inferir que os ambientes virtuais de aprendizagem ainda são pouco explorados por essas comunidades, considerando que apenas 16,7\%, lecionam na modalidade B-learning e $11,1 \%$ na modalidade E-learning. Em um estudo realizado por Manca e Ranieri (2016) com professores do ensino superior italiano intitulado "Yes for sharing, no for teaching! Social Media in academic practices" foi constatado que os estudiosos estão mais inclinados a adotar as Media Social para usos pessoais e profissionais e não para as práticas de ensino e, que o uso prévio de uma plataforma $E$ learning institucional foi associado à frequência de utilização de várias ferramentas on-line, com exceção da Academia.Edu e da ResearchGate, com usos considerados irrelevantes, e que o mesmo ocorreu com a modalidade B-learning. 
Os dados apresentados na Tabela 5 evidenciam que dos 39 respondentes, $18 / 46,2 \%$, possuem perfil na ResearchGate e $21 / 53,8 \%$ não possuem. Dentre os que possuem perfil, a maioria $(13 / 72,2 \%)$ dos inquiridos, cadastrou-se há mais de dois anos. Quando questionados sobre as Redes sociais, além da ResearchGate que utilizam para promover a visibilidade e internacionalização do trabalho acadêmico e científico desenvolvido, a maioria dos inquiridos, $12 / 70,6 \%$, utiliza o Google Scholar, 11/64,7\%, a LinkedIn, 10/58,8\% o Facebook e 9/52,9\%, a Academia.Edu.

Tabela 5 - Perfil na ReseachGate e em outras Redes Rociais, e tempo de uso

\begin{tabular}{|c|c|c|c|c|c|c|c|c|c|c|}
\hline \multicolumn{3}{|c|}{$\begin{array}{c}\text { Perfil na ResearchGate } \\
\text { N\% }\end{array}$} & \multicolumn{3}{|c|}{$\begin{array}{c}\text { Tempo/Perfil na ResearchGate } \\
\text { N\% }\end{array}$} & \multicolumn{5}{|c|}{$\begin{array}{l}\text { Perfil em outras Redes Sociais } \\
\text { N\% }\end{array}$} \\
\hline Sim & 18 & 46,2 & $\begin{array}{c}\text { Menos de } 6 \\
\text { meses }\end{array}$ & 0 & 0 & 1.1.1 & $\underline{B \log s}$ & $1.1 .2 \underline{2}$ & 1.1.3 & $\underline{111,8}$ \\
\hline \multirow[t]{7}{*}{ Não } & 21 & 53,8 & $\begin{array}{c}\text { Há mais de } 6 \\
\text { meses }\end{array}$ & 2 & 11,1 & 1.1 .4 & $\frac{\text { Twitte }}{\underline{r}}$ & $\begin{array}{ll}1.1 .5 & 4\end{array}$ & 1.1 .6 & $\underline{23,5}$ \\
\hline & & & $\begin{array}{l}\text { Há mais de } 1 \\
\text { ano }\end{array}$ & 3 & 16,7 & 1.1.7 & $\frac{\text { Linke }}{d \ln }$ & $1.1 .8 \quad \underline{11}$ & 1.1 .9 & $\underline{64,7}$ \\
\hline & & & $\begin{array}{c}\text { Há mais de } 2 \\
\text { anos }\end{array}$ & 13 & 72,2 & 1.1 .10 & $\frac{\overline{\text { Acad }}}{\frac{\text { emia. }}{\text { edu }}}$ & $\begin{array}{ll}1.1 .11 \quad \underline{9}\end{array}$ & 1.1 .12 & $\underline{52,9}$ \\
\hline & & & & & & 1.1 .13 & $\frac{\text { Faceb }}{\text { ook }}$ & $1.1 .14 \quad \underline{10}$ & 1.1 .15 & $\underline{58,8}$ \\
\hline & & & & & & 1.1 .16 & $\frac{\overline{\text { YouT }}}{\text { ube }}$ & $1.1 .17 \quad \underline{2}$ & 1.1 .18 & $\underline{11,8}$ \\
\hline & & & & & & 1.1.19 & $\begin{array}{l}\frac{\text { Googl }}{\frac{e}{\text { schol }}} \\
\frac{a r}{}\end{array}$ & $1.1 .20 \quad \underline{12}$ & 1.1 .21 & $\underline{70,6}$ \\
\hline & & & & & & 1.1 .22 & $\frac{\text { Outra }}{\underline{s}}$ & $1.1 .23 \quad \underline{1}$ & 1.1 .24 & $\underline{5,9}$ \\
\hline
\end{tabular}

Fonte: Dados da pesquisa.

Portanto, os profissionais estão empregando as redes sociais acadêmicas e profissionais, a fim de alargar as suas redes, aprender sobre seus pares e com os pares, localizar especialistas para resolver problemas, e encontrar potenciais colaboradores. Dentre esses usuários especializados que utilizam redes acadêmicas, estão os órgãos científicos ou acadêmicos, pois estes ambientes proporcionam a essas comunidades ferramentas de trabalho cooperativo, por meio da qual podem desempenhar um papel crítico na especificação de maneiras de como resolver problemas nesses ambientes, aumentando o nível de sucesso e realização dos objetivos individuais e em grupo (ALMOUSA, 2011).

O Facebook está entre as redes sociais mais utilizadas e visitadas por estudiosos do ensino superior para fins pessoais, enquanto que para fins profissionais tem-se a LinkedIn. No entanto, a frequência de uso dessas Redes está principalmente associada ao uso profissional e, não aos fins ensino. Estes resultados mostram uma atitude geralmente mais favorável à partilha pessoal e ao desenvolvimento profissional através de redes sociais on-line. Estes dados, vêm corroborar os apresentados por esta pesquisa, como pode-se observar na Tabela 4, que dentre as redes 
sociais mais utilizadas pelos respondentes, estão também a LinkedIn e o Facebook (MANCA; RANIERI, 2016).

Em resposta à questão colocada sobre a intensidade de uso da ResearchGate, a Tabela 6 , demostra que $8 / 47,1 \%$ dos respondentes afirmam utilizar raramente e $47 / 23,5 \%$, algumas vezes por semana, e, todos os dias, apenas $2(11,8 \%)$. Já em relação ao número de documentos disponibilizados na ResearchGate, 5/33,3\% disponibilizam menos de 5 documentos de sua autoria (coautoria) e 5/27,8\% disponibilizam mais de 30 documentos.

Tabela 6 - Intensidade de uso e número de documentos disponibilizados na ResearchGate

\begin{tabular}{l|l|l|l|l|l}
\hline \multicolumn{2}{c}{$\begin{array}{c}\text { Intensidade de uso } \\
\text { N\% }\end{array}$} & \multicolumn{2}{c}{$\begin{array}{c}\text { No. de documentos(autoria/coautoria) } \\
\text { Disponibilizados na ResearchGate } \\
\text { N\% }\end{array}$} \\
\hline \hline Não aplicável & 1 & 5,9 & Menos de 5 & 5 & 33,3 \\
\hline Nunca & 2 & 11,8 & Entre 5 e 10 & 3 & 16,7 \\
\hline Raramente & 8 & 47,1 & Entre 11 e 20 & 2 & 11,1 \\
\hline $\begin{array}{l}\text { Algumas vezes por } \\
\text { semana }\end{array}$ & 4 & 23,5 & Entre 21 e 30 & 11,1 \\
\hline Todos os dias & \multicolumn{7}{l}{ Fonte: Dados da pesquisa. } & 5 & 27,8 \\
\hline
\end{tabular}

Estudos como o de Thelwall e Kousha (2014), Almousa (2011) e Manca e Ranieri (2016), revelam que as Redes Sociais Acadêmicas estão cada vez sendo mais utilizadas em ambientes universitários por pesquisadores e acadêmicos para fins de disponibilização de documentos e interação entre pares. Apesar de o Facebook ainda ser uma das redes sociais mais utilizadas para uso pessoal, pois seu uso diário ultrapassa os usos diários, semanais e mensais de qualquer outra media social por professores para fins pessoais. Em relação ao uso profissional, o Facebook foi o mais utilizado até 2012, sendo substituído pela LinkedIn. Segundo o ranking global da Alexa.com, com dados de 2011 demonstram que a Academia.edu, a LinkedIn, e a ResearchGate estão se tornando cada vez mais populares, com um ranking global de 7982, 16 e 16324 respectivamente.

Quanto ao número de pessoas por quem são seguidos, pode-se perceber na Tabela 7 , que a maioria $11 / 64,7 \%$, possui até 30 seguidores, já em relação ao número de pessoas que segue, a maioria 9/52,9\% tem também até 30 seguidores. 
Tabela 7 - Número de pessoas que seguem e por quem são seguidos

\begin{tabular}{l|l|l|l|l|l|l|l|l|l|l}
\hline & \multicolumn{2}{|c|}{$\begin{array}{c}\text { Até 30 } \\
\text { N\% }\end{array}$} & \multicolumn{2}{|c|}{$\begin{array}{c}\text { Entre 31 e 80 } \\
\text { N\% }\end{array}$} & \multicolumn{2}{c|}{$\begin{array}{c}\text { Entre 81 e 150 } \\
\text { N\% }\end{array}$} & \multicolumn{2}{c|}{$\begin{array}{c}\text { Entre 151 e 250 } \\
\text { N\% }\end{array}$} & \multicolumn{2}{c}{$\begin{array}{c}\text { Mais de 250 } \\
\text { N\% }\end{array}$} \\
\hline \hline $\begin{array}{l}\text { Número de pessoas } \\
\text { que segue }\end{array}$ & 11 & 64,7 & 3 & 17,6 & 2 & 11,8 & 0 & 0 & 1 & 5,9 \\
\hline $\begin{array}{l}\text { Número de pessoas } \\
\text { por quem são } \\
\text { seguidos }\end{array}$ & 9 & 52,9 & 4 & 23,5 & 2 & 11,8 & 2 & 11,8 & 0 & 0 \\
\hline
\end{tabular}

Fonte: Dados da pesquisa.

Em relação ao número de visualizações das suas publicações na Researchgate, 5/31,3\%, encontra-se em torno de 2001 a 4000 . Quanto ao valor do seu RG Score, que demonstra o grau de representatividade dos docentes/investigadores diante dos seus pares, a maioria $4 / 23,5 \%$ está entre 6 e 8 (Tabela 8 ).

Tabela 8 - Número de visualizações das publicações e valor do seu RG Score na ReseachGate

\begin{tabular}{|c|c|c|c|c|c|}
\hline \multicolumn{3}{|c|}{$\begin{array}{l}\text { Número de visualizações das publicações } \\
\text { N\% }\end{array}$} & \multicolumn{3}{|c|}{$\begin{array}{c}\text { Valor do RG Score } \\
\text { N\% }\end{array}$} \\
\hline Inferior a 100 & 3 & 18,8 & Não tenho RG Score & 3 & 17,6 \\
\hline Entre 101 e 300 & 2 & 12,5 & RG Score até 3 & 3 & 17,6 \\
\hline Entre 301 e 800 & 2 & 12,5 & RG Score entre 3 e 5 & 3 & 17,6 \\
\hline Entre 801 e 1300 & 3 & 18,8 & RG Score entre 6 e 8 & 4 & 23,5 \\
\hline Entre 1301 e 2000 & 0 & 0 & RG Score entre 9 e 11 & 2 & 11,8 \\
\hline Entre 2001 e 4000 & 5 & 31,3 & RG Score entre 12 e 14 & 2 & 11,8 \\
\hline Entre 4001 e 6000 & 0 & 0 & RG Score entre 15 e 17 & 0 & 0 \\
\hline Entre 6001 e 8000 & 1 & 6,3 & RG Score entre 18 e 19 & 0 & 0 \\
\hline Mais de 8000 & 0 & 0 & RG Score superior a 20 & 0 & 0 \\
\hline
\end{tabular}

Fonte: Dados da pesquisa.

As Tabelas 7 e 8 apresentam a representatividade dos docentes/investigadores frente aos seus pares, traduzidos em número de pessoas que seguem e por quem são seguidos, bem como o número de visualizações das suas publicações e o valor do seu RG Score, verifica-se nessa comunidade que já existe uma prática desses docentes/investigadores com o uso da ResearchGate, para interação entre pares, divulgação de suas publicações, tornando-os assim visíveis e adquirindo representatividade diante de seu pares, ainda que em escalas pequenas. Manca e Ranieri (2016) apresentam vários estudos como os de Greenhow e Gleason (2014), Grudz et al., (2012), Li e Greenhow (2015), Veletsianos (2012/2013) que abordam o papel e a função social das medias sociais nas vidas acadêmicas. Autores como Fitzmaurice (2013), Forkosh-Baruch e Hershkoviyz (2012), Kirkup (2010) e Kjellberg (2010) descobriram que acadêmicos que utilizam as mídias sociais incluindo, sites de redes sociais acadêmicos são mais engajados com seus pares, procurando fortalecer e melhorar a sua identidade profissional, com o intuito de se tornarem "intelectuais públicos", aumentando, assim, a sua visibilidade externa.

Confrontando os dados das Tabelas 7 e 8 com as avaliações feitas pelos respondentes sobre o contributo das redes sociais acadêmicas para 
o estabelecimento e fortalecimento de parcerias, estes enfatizaram em suas falas que elas permitem "estabelecer relações com colegas que tenham interesse de investigação comuns. Podem também ser um facilitador para investigadores juniores contactarem investigadores seniores, em especial de outros países. Serão igualmente uma ferramenta útil na divulgação do trabalho pessoal e na descoberta de novos trabalhos. Mas para conseguir tirar partido de todas estas potencialidades, é necessário investir muito tempo na manutenção dos dados pessoais e para dinamizar contatos".

Em relação ao grau de motivação, os respondentes consideram fundamental poder disponibilizar suas publicações com o intuito de dar visibilidade em uma rede alargada $(8 / 47,1 \%)$, importante e fundamental ser notificado das novas publicações dos pares $(4 / 23,5 \%)$, irrelevante e pouco significativo poder acompanhar a divulgação de oportunidades de emprego e bolsas $(6 / 35,3 \%$ e $5 / 29,4)$, bem como poder exportar o seu CV a partir dos dados do seu perfil. (Tabela 9).

Tabela 9 - Grau de motivação para disponibilização e acesso a documento em e informação na ResearchGate

\begin{tabular}{|c|c|c|c|c|c|c|c|c|c|c|c|c|}
\hline & \multicolumn{2}{|c|}{$\begin{array}{l}\text { Irrelevante } \\
\text { N\% }\end{array}$} & \multicolumn{2}{|c|}{$\begin{array}{c}\text { Pouco } \\
\text { significativo } \\
\text { N\% }\end{array}$} & \multicolumn{2}{|c|}{$\begin{array}{c}\text { Importante } \\
\mathbf{N} \%\end{array}$} & \multicolumn{2}{|c|}{$\begin{array}{c}\text { Muito } \\
\text { importante } \\
\text { N\% }\end{array}$} & \multicolumn{2}{|c|}{$\begin{array}{l}\text { Muitíssimo } \\
\text { importante } \\
\mathrm{N} \%\end{array}$} & \multicolumn{2}{|c|}{$\begin{array}{c}\text { Fundamenta } \\
\mathrm{N} \%\end{array}$} \\
\hline $\begin{array}{l}\text { publicações dando-lhe } \\
\text { visibilidade numa rede } \\
\text { alargada }\end{array}$ & 3 & 17,6 & 1 & 5,9 & 3 & 17,6 & 0 & 0 & 2 & 11,8 & 8 & 47,1 \\
\hline $\begin{array}{l}\text { Ser notificado(a) das } \\
\text { novas publicações } \\
\text { dos investigadores } \\
\text { que fazem parte da } \\
\text { minha rede na } \\
\text { ResearchGate }\end{array}$ & 1 & 5,9 & 3 & 17,6 & 4 & 23,5 & 3 & 17,6 & 2 & 11,8 & 4 & 23,5 \\
\hline $\begin{array}{l}\text { Acompanhar a } \\
\text { divulgação de } \\
\text { oportunidades de } \\
\text { emprego e bolsas } \\
\text { divulgadas }\end{array}$ & 6 & 35,3 & 5 & 29,4 & 3 & 17,6 & 2 & 11,8 & 0 & 0 & 1 & 5,9 \\
\hline $\begin{array}{l}\text { Poder exportar o meu } \\
\text { CV que é elaborado a } \\
\text { partir dos dados do } \\
\text { meu perfil (Export } \\
\text { your profile as a CV) }\end{array}$ & 6 & 35,3 & 5 & 29,4 & 1 & 5,9 & 2 & 11,8 & 2 & 11,8 & 1 & 5,9 \\
\hline
\end{tabular}

Fonte: Dados da pesquisa.

Quanto ao grau de motivação dos inquiridos para interação entre pares na ResearchGate, em especial aqueles que possuem interesses de investigação próximos às linhas de pesquisas que desenvolvem, observase que, somando as respostas dos inquiridos que consideraram importante, muito importante, muitíssimo importante e fundamental, temse uma avaliação positiva nesse ponto, perfazendo um percentual de $12 / 70,5 \%$. Enquanto que em relação a encontrar trabalhos científicos, os inquiridos em sua maioria afirmaram ser muito importante e fundamental. Somando essas posições obtém-se um percentual relevante de $9 / 53 \%$, já em relação a participação em Fóruns, estes consideram irrelevante e pouco significativo (Tabela 10). 
Tabela 10 - Grau de motivação para interação entre investigadores na ResearchGate

\begin{tabular}{|c|c|c|c|c|c|c|c|c|c|c|c|c|}
\hline \multirow{2}{*}{$\begin{array}{l}\text { Encontrar } \\
\text { investigadores que } \\
\text { tenham interesses } \\
\text { de investigação } \\
\text { próximos dos meus }\end{array}$} & \multicolumn{2}{|c|}{$\begin{array}{l}\text { Irrelevante } \\
\text { N\% }\end{array}$} & \multicolumn{2}{|c|}{$\begin{array}{c}\text { Pouco } \\
\text { significativo } \\
\text { N\% }\end{array}$} & \multicolumn{2}{|c|}{$\begin{array}{l}\text { Importante } \\
\text { N\% }\end{array}$} & \multicolumn{2}{|c|}{$\begin{array}{c}\text { Muito } \\
\text { importante } \\
\mathrm{N} \%\end{array}$} & \multicolumn{2}{|c|}{$\begin{array}{c}\text { Muitíssimo } \\
\text { importante } \\
\mathrm{N} \%\end{array}$} & \multicolumn{2}{|c|}{$\begin{array}{c}\text { Fundamental } \\
\mathrm{N} \%\end{array}$} \\
\hline & 2 & 11,8 & 3 & 17,6 & 2 & 11,8 & 4 & 23,5 & 3 & 17,6 & 3 & 17,6 \\
\hline $\begin{array}{l}\text { Encontrar trabalhos } \\
\text { científicos (artigos, } \\
\text { teses, etc.) de forma } \\
\text { ágil e com acesso } \\
\text { livre }\end{array}$ & 2 & 11,8 & 2 & 11,8 & 1 & 5,9 & 4 & 23,5 & 3 & 17,6 & 5 & 29,4 \\
\hline $\begin{array}{l}\text { Participar no Fórum } \\
\text { de Questões e } \\
\text { Respostas (Q\&A) }\end{array}$ & 5 & 29,4 & 6 & 35,3 & 2 & 11,8 & 3 & 17,6 & 1 & 5,9 & 0 & 0 \\
\hline
\end{tabular}

Fonte: Dados da pesquisa.

Os dados apresentados nas Tabelas 9 e 10 referentes aos graus de motivação dos respondentes para disponibilizar as suas publicações, para fins de visibilidade, serem notificados de novas publicações por seus pares e, encontrar investigadores que desenvolvam linhas de pesquisas próximas de suas linhas de investigação foram considerados relevantes, quando confrontados com as respostas abertas no campo destinado a levantar opiniões destes sobre o papel das Redes Sociais acadêmicas online pelos respondentes. Pode-se perceber em seus comentários que estes valorizam as redes acadêmicas como ambientes de interação, partilha e disponibilização de documentos na contemporaneidade como fundamentais para "ajuda a manter-se informado de seu campo de interesses, recuperar/solicitar estudos importantes gratuitamente com os próprios autores, reforço da partilha de conhecimento dentro de microcomunidades académicas, [bem como as consideram] são vitais no contexto atual da pesquisa [e possibilitam] a comunicação, divulgação e o acesso rápido e fácil à informação."

No que refere ao grau de mais-valia da ResearchGate, para dar visibilidade junto a outros investigadores dos trabalhos desenvolvidos $4 / 23,5 \%$, consideram muitíssimo importante e 6/35,3 fundamental. Quanto a mais-valia dessa Rede, para a promoção e internacionalização da produção científica gerada, para fins de visibilidade, reconhecimento e prestígio, $4 / 23,5 \%$ dos inquiridos consideram muitíssimo importante e outros $5 / 29,4 \%$ fundamental. Relativamente a sua mais-valia, quanto a usufruir do Sistema "Score" que mede a relevância na comunidade científica, para fins de visibilidade, internacionalização, reconhecimento e prestígio ao trabalho desenvolvido $6 / 35,3 \%$ dos inquiridos consideraram pouco relevante e $4 / 23,5 \%$ fundamental. Entretanto, quando se somam as posições que consideram importante, muito importante, muitíssimo importante e fundamental obtém-se um valor de 10/58,9\% que pode ser considerada uma perspectiva bastante positiva do Sistema de "Score" (Tabela 11). 
Tabela 11 - Grau de mais-valia da ResearchGate para visibilidade e internacionalização do trabalho desenvolvido

\begin{tabular}{l|l|l|l|l|l|l|l|l|l|l|l|l}
\hline & \multicolumn{2}{|c|}{$\begin{array}{c}\text { Irrelevante } \\
\text { N\% }\end{array}$} & \multicolumn{2}{|c|}{$\begin{array}{c}\text { Pouco } \\
\text { significativo } \\
\text { N\% }\end{array}$} & \multicolumn{2}{|c|}{$\begin{array}{c}\text { Importante } \\
\text { N\% }\end{array}$} & \multicolumn{2}{|c|}{$\begin{array}{c}\text { Muito } \\
\text { importante } \\
\text { N\% }\end{array}$} & $\begin{array}{l}\text { Muitíssimo } \\
\text { importante } \\
\text { N\% }\end{array}$ & \multicolumn{2}{|c|}{$\begin{array}{c}\text { Fundamental } \\
\text { N\% }\end{array}$} \\
\hline $\begin{array}{l}\text { Dar visibilidade ao } \\
\text { meu trabalho junto } \\
\text { dos outros } \\
\text { investigadores }\end{array}$ & 1 & 5,9 & 3 & 17,6 & 2 & 11,8 & 1 & 5,9 & 4 & 23,5 & 6 & 35,3 \\
\hline $\begin{array}{l}\text { Promover a } \\
\text { internacionalização da } \\
\text { minha produção } \\
\text { científica }\end{array}$ & 1 & 5,9 & 4 & 23,5 & 2 & 11,8 & 1 & 5,9 & 4 & 23,5 & 5 & 29,4 \\
\hline $\begin{array}{l}\text { Usufruir do sistema de } \\
\text { "Score" que mede a } \\
\text { relevância na } \\
\text { comunidade científica }\end{array}$ & 1 & 5,9 & 6 & 35,3 & 2 & 11,8 & 2 & 11,8 & 2 & 11,8 & 4 & 23,5 \\
\hline
\end{tabular}

Fonte: Dados da pesquisa.

Os resultados apresentados nas Tabelas 9 e 10 e 11 remetem ao impacto dos estudos de métrica baseada na web como uma maneira eficaz de apresentar, em especial aquelas que se apropriam das mídias sociais para avaliar o impacto dos produtos científicos, ou seja, a maturidade destas métricas abrem caminhos para que sejam reavaliadas as medições sobre a produtividade e autoridade dos pesquisadores, evidenciando, assim, qual o impacto científico das métricas focadas nas atividades de mídia social, ou seja, como os rastros deixam visível a produção dos pesquisadores em páginas da web, como: blogs, downloads, redes sociais (Twitter, Facebook, dentre outras), gerenciadores de referências bibliográficas (CiteULike, Mandeley e Zotero) (BARROS, 2015, p. 20-21)

Outro ponto a ser considerado é que atualmente o Conselho Nacional de Desenvolvimento Científico e Tecnológico (CNPQ), no Brasil, passou a adotar como um dos itens de avaliação "as iniciativas de educação e divulgação científica realizadas pelos próprios cientistas", pois se antes era valorizado somente a produtividade acadêmica na avaliação de desempenho, hoje o pesquisador necessita ter consciência da "importância de fazer divulgação on-line de seus produtos de pesquisa". Isso permite que se considere as mídias sociais como ferramentas indispensáveis à avaliação da representatividade e autoridade do cientista frente aos seus representantes, sejam estes seus pares ou instituições que o representem ou que institucionalizem as suas pesquisas (BARROS, 2015, p. 21).

Há de se considerar, que as Redes acadêmicas, em especial a ResearchGate, é uma plataforma de comunicação que impulsiona em uma escala mais alargada a troca de experiências entre pares por meio do diálogo, possibilitando o confronto de ideias de forma ética, estimulando a criticidade, a produção de conhecimentos, o que leva as comunidades científicas em análise, a diversidade de investigações em áreas ainda não exploradas, e o amadurecimento intelectual.

Quando questionados sobre a frequência de utilização das ferramentas infocomunicacionais para fins de comunicação, interação e 
partilha entre pares, os dados apresentados na Tabela 12 demonstram que, dentre as utilizadas raramente e algumas vezes por mês e por semana, estão: ferramentas de publicação e partilha de conteúdo, ferramentas colaborativas e ferramentas de agregação de conteúdo. No entanto, a mais utilizada todos os dias, dentre as dispostas na referida tabela está a de comunicação interpessoal com um total de 11/64,7\%.

Tabela 12 - Frequência de utilização de ferramentas infocomunicacionais como suporte à comunicação, interação e partilha entre pares

\begin{tabular}{l|l|l|l|l|l|l|l|l|l|l|l|l|l}
\hline & \multicolumn{2}{|c|}{$\begin{array}{c}\text { Não } \\
\text { aplicável } \\
\text { N\% }\end{array}$} & \multicolumn{2}{|c|}{$\begin{array}{c}\text { Nunca } \\
\text { N\% }\end{array}$} & \multicolumn{2}{c|}{$\begin{array}{c}\text { Raramente } \\
\text { N\% }\end{array}$} & $\begin{array}{c}\text { Algumas } \\
\text { vezes por } \\
\text { mês } \\
\text { N\% }\end{array}$ & \multicolumn{2}{|c|}{$\begin{array}{c}\text { Algumas } \\
\text { vezes por } \\
\text { semana } \\
\text { N\% }\end{array}$} & $\begin{array}{c}\text { Todos os } \\
\text { dias } \\
\text { N\% }\end{array}$ \\
\hline $\begin{array}{l}\text { Ferramentas de publicação } \\
\text { e partilha de conteúdos }\end{array}$ & 3 & 17,6 & 0 & 0 & 4 & 23,5 & 5 & 29,5 & 1 & 5,9 & 4 & 23,5 \\
\hline Ferramentas colaborativas & 2 & 11,8 & 3 & 17,6 & 4 & 23,5 & 3 & 17,6 & 3 & 17,6 & 2 & 11,8 \\
\hline Redes sociais & 1 & 5,9 & 1 & 5,9 & 6 & 35,3 & 1 & 5,9 & 2 & 11,8 & 6 & 35,3 \\
\hline $\begin{array}{l}\text { Ferramentas de } \\
\text { comunicação interpessoal }\end{array}$ & 0 & 0 & 0 & 0 & 3 & 17,6 & 3 & 17,6 & 0 & 0 & 11 & 64,7 \\
\hline $\begin{array}{l}\text { Ferramentas de agregação } \\
\text { de conteúdos }\end{array}$ & 2 & 11,8 & 4 & 23,5 & 3 & 17,6 & 3 & 17,6 & 4 & 23,5 & 1 & 5,9 \\
\hline
\end{tabular}

Manca e Ranieri (2016) evidenciam que na comunidade de professores universitários italianos investigados por estes, a associação entre os tipos de utilização, depende tipo de ferramenta, por exemplo, o Podcast, Blogue, Wiki, YouTube, Vimeo e SlideShare, que são ferramentas caracterizadas principalmente pelo conteúdo e recursos de compartilhamento e de produção está associada entre o uso pessoal e de ensino de forma bem significativa, pois estas são mais adaptadas às práticas de ensino. Já o Facebook e Twitter, de uso pessoal e profissional, prevalece. Isso demonstra a compatibilidade entre tarefa e tecnologia.

De acordo com os resultados apresentados, pode-se inferir que as Redes sociais acadêmicas promovem a partilha de informação e conhecimento, caracterizados como motores do novo paradigma imaterial, no qual o valor centra-se na circulação de conhecimentos e informações entre comunidades da mesma área de conhecimento ou áreas afins, de forma dinâmica e cíclica, proporcionando o diálogo, o debate e a geração de novos conhecimentos (OLIVEIRA, 2004).

Para tanto, os inquiridos evidenciaram que as redes sociais acadêmicas, em especial a ResearchGate, foco deste estudo, é uma maisvalia para o alargamento do processo de comunicação entre pares nas comunidades científicas. Entretanto, utilizam outras como: Google Scholar, LinkedIn, o Facebook e a Acadêmia.edu., com índices de uso até mais representativos, conforme demonstrados na Tabela 4. Estes nas questões abertas quando questionados em especial sobre o contributo da ResearchGate, para fins de visibilidade e internacionalização dos seus produtos científicos afirmaram que resistem em "chamar ResearchGate e semelhantes de "rede social", pois não as uso com este fim. Cada um tem suas vantagens, mas não compreendo por que ResearchGate faz tanto 
sucesso, pois para mim é quase nulo. Google Scholar é o que mais considero".

Percebe-se com os resultados apresentados por este estudo, que os respondentes possuem pontos de vistas diferenciados acerca das potencialidades das redes sociais listadas em ambientes de ensino e pesquisa. Cada um apresenta seus discursos emanados a partir das questões abertas, ou, a partir dos percentuais de aceitação e motivações para uso das redes sociais listadas as suas preferências. Contudo, há um consenso entre estes, no sentido de apontarem as mais-valias desses ambientes digitais, como mecanismos que alargam, agilizam e impulsionam parcerias, a partir dos interesses em comuns de pesquisas ou das necessidades de publicações em coautoria. Tais aspectos são motores do aumento da representatividade e visibilidade destes diante das comunidades científicas das quais fazem parte, das instituições a que pertencem ou das instituições de fomento à pesquisa em escala nacional e internacional.

\section{Conclusões}

O presente estudo procurou responder aos objetivos traçados nesta investigação delineados referentes às motivações, às percepções e ao contributo da Rede Social Acadêmica on-line ResearchGate. Dessa forma, procurou-se evidenciar a relevância acadêmica e científica dessa plataforma de comunicação social como uma mais-valia para o reconhecimento e visibilidade dos docentes/investigadores que atuam na área de Biblioteconomia e Ciência da Informação, vinculados a IES públicas e privadas brasileiras e portuguesas.

De acordo com os objetivos traçados e, considerando-se as categorias estabelecidas para a análise e discussão dos dados coletados, pode-se perceber de acordo com a questão aberta referente às categorias "perfil dos respondentes" e "perfil na ResearchGate", que os mesmos possuem como áreas de investigação de interesse predominantemente "Ciências da Comunicação e Informação, Sistemas de informação, Comportamento Infocomunicacional, Convergência dos Media e Cibercultura, Biblioteconomia, Cultura e Sociedade, Gestão da informação, Políticas de informação, Comportamento informacional, Uso da Informação, Comunicação científica, Políticas Bibliotecárias, Linguagens documentais, Bibliometria, Ciências da documentação, Interação e compartilhamento da informação em Redes Sociais, Organização da informação, Livros digitais, Literacia da Informação", dentre outras o que nos leva a inferir que os profissionais que possuem Perfil em Redes sociais on-line atuam em linhas de pesquisas diversificadas, pertencentes as áreas científicas investigadas.

Outro ponto que merece evidenciarmos, é que esta pesquisa foi realizada em duas fazes, conforme discriminadas nos procedimentos metodológicos, a primeira foi realizada na própria Rede, para identificarmos docentes/investigadores da área em estudo que possuíam 
perfil nessa Plataforma. Localizamos então 27 brasileiros e 21 portugueses (Tabelas 2 e 3). Depois foi realizado um levantamento das Escolas de Graduação e Pós-Graduação brasileiras e portuguesas (Quadros 2, 3 e 4), para as quais foram encaminhados e-mails com o link do questionário utilizado nesta pesquisa, assim como também para todos os sujeitos localizados com perfis nessa Rede. Sendo assim, de todos os e-mails encaminhados, obtivemos 39 respostas ao referido questionário, destas apenas 18/46,2\% (Tabela 5) possuem perfil na ResearchGate.

Relativamente às categorias "usos e motivações" que fazem da ReseachGate, confrontando-se os dados das questões fechadas apresentadas nas tabelas com as respostas das questões abertas, pode-se afirmar que os mesmos consideram essa Rede como uma mais-valia para a divulgação da produção científica em larga escala, a comunicação e a interação entre investigadores que possuem interesses de investigação próximos dos seus, favorecendo a criação de grupos de pesquisa em âmbito nacional e internacional. Esta permite também reconhecimento e prestígio entre pares. Considerando que um dos parâmetros de avaliação considerados pelo CNPq na atualidade é a capacidade e criatividade dos cientistas em criar seus perfis públicos nas mídias sociais com o intuito de avaliar a representatividade e autoridade do cientista frente aos seus pares e representantes, isso significa que "cuidar da reputação na internet é muito mais que exercício de vaidade ou ostentação, é um trabalho que pode contribuir para a sobrevivência da investigação científica, ajudando a sociedade como um todo a perceber melhor o papel dos cientistas enquanto agentes de mudança e inovação" (SANCHEZ; GRANADO; ANTUNES, 2014, p. 6).

Tem-se que levar em consideração também que os resultados apresentados nesta pesquisa corroboram resultados apresentados em outras pesquisas em nível nacional e internacional, apresentados na revisão de literatura deste artigo e na apresentação dos resultados e discussão dos seus dados coletados. Assim, pode-se evidenciar ainda um uso diminuto das redes sociais em ambientes universitários para fins de ensino, mas um uso bem expressivo para fins pessoais e profissionais, ponto propício a uma reflexão sobre as razões que estão impedindo a plena adoção dessas plataformas de mídias sociais na contemporaneidade em se tratando de ambientes universitários.

Em relação a ReseachGate, pode-se inferir que os respondentes são conscientes das potencialidades apresentadas por essa mídia social, e apresentam-se motivados. Consideram fundamental dar visibilidade promover a internacionalização das suas publicações e encontrar trabalhos científicos em open access. Entretanto, quando se cruzam os dados das Tabelas 5 a 11, percebe-se que apesar de serem motivados, possuírem perfis a mais de dois anos, disponibilizarem as suas publicações, por outro lado não possuem frequência de uso. Dentre os fatores apresentados pelos respondentes para o não uso desse ambiente digital está a necessidade de investimento de tempo tanto para a manutenção, quanto para a dinamização dos contatos estabelecidos. Para que de fato ocorra 
um diferencial conforme objetivo traçado neste estudo, para comunicar, partilhar e fazer ciência na sociedade dita em Rede, ou do Conhecimento, é necessário que as comunidades científicas estudadas, incorporem a cultura digital em suas atividades, só assim efetivariam os discursos apresentados nas questões abertas, onde se destacam todas as maisvalias dos usos desses ambientes, com o intuito de tornarem a ciência mais colaborativa e pública.

Na globalidade, pode-se inferir que as redes sociais on-line são um espaço antropológico que possibilitam a ligação entre os investigadores, permitindo transformar as práticas de colaboração e cooperação, gerando visibilidade, o que potencia o aumento do capital social destes indivíduos e cria valor no seio das comunidades científicas investigadas. Além de estimular a parceria entre instituições de estudo e pesquisa, neste caso da área de Biblioteconomia e Ciência da Informação, acarretando avanços para a ciência e desenvolvimento das IES envolvidas.

\section{Referências}

ALCARÁ, A. R. et al. Fatores que influenciam o compartilhamento da informação e do conhecimento. Perspectivas em Ciência da Informação, v. 14, n. 1, p. 170-191, abr. 2009. Disponível em: <http://www.scielo.br/pdf/pci/v14n1/v14n1a12>. Acesso em 21 mar. 2016.

ALMOUSA, O. Users' Classification and usage-pattern identification in Academic Social Networks. IEEE Jordan Conference on Applied Electrical Engineering and Computing Technologies (AEECT). 2011. Disponível em: $<$ http://ieeexplore.ieee.org/xpls/icp.jsp?arnumber=6132525>. Acesso em: 24 nov. 2015.

ARAÚJO, P. C. de. O Blog "na ERA DA INFORMAÇÃO" como ferramenta de compartilhamento de informação, conhecimento e para a promoção profissional. Revista ACB: Biblioteconomia em Santa Catarina, v. 15, n. 1, p. 201-213, 2010.

BASTOS, B. B. ; OLIVEIRA, L. de J. A comunidade científica no contexto da mediação comunicacional global - afecção das dinâmicas cognitivas e sociais. In: CONFERÊNCIAS LUSÓFONA, 6., SOPCOM, 4. , IBÉRICO, 2009, Lisboa. Actas... 2009. p.3677-3699. Disponível em: $<$ http://conferencias.ulusofona.pt/index.php/sopcom_iberico/sopcom_iberico09/paper /view/307 > Acesso em: 20 mar. 2015.

BIRKHOLZ, J. M. et al. Whoarewetalkingabout?: identifyingscientific populations online. Semantic Web and Web Science, p. 237-250, May 2013. Disponível em: $<$ http://link.springer.com/chapter/10.1007\%2F978-1-4614-6880-6 21>. Acesso em 20 Mar. 2016.

BORGES, M. E. N. O essencial para a gestão de serviços e produtos de informação. Revista Digital de Biblioteconomia e Ciência da Informação, v. 5, n. 1, p. 115-128, jul./dez. 2007. Disponível

em: $<$ https://periodicos.sbu.unicamp.br/ojs/index.php/rdbci/article/view/2007>. Acesso em: 24 nov. 2015. 
BUFREM, L. S.; GABRIEL JUNIOR, R. F.; SORRIBAS, T. V. Redes sociais na pesquisa científica da área de ciência da informação. DataGramaZero - Revista de Informação, v. 12, n. $3, \quad 2011 . \quad$ Disponível em: <http://www.dgz.org.br/ago11/Art_01.htm>. Acesso em: 24 nov. 2015.

CASTELLS, M. A Sociedade em rede. 6.ed. São Paulo: Paz e Terra, 1999.

CHINCHILLA-RODRÍGUEZ, Z. , MIGUEL, S., MOYA-ANEGÓN, F. de. What factors affect the visibility of Argentinean publications in humanities and social sciences in Scopus? Some evidence beyond the geographic realm of research. Scientometrics, v. 102, n. 1, p. 789-810, 2015. <Disponível em: <https://link.springer.com/article/10.1007/s11192-014-1414-4>. Acesso em: 24 mar. 2015.

DONELAN, H. Social media for professional development and networking opportunities in academia. Journal of Further and Higher Education, v. 40, n. 5, p. 706-729, April 2015. Disponível em: $<$ http://www.tandfonline.com/doi/abs/10.1080/0309877X.2015.1014321>. Acesso em: 24 mar. 2015.

GOMES, C. M. Comunicação científica: alicerces, transformações e tendêcias. Covilhã, Portugal: Livros LABCOM books, 2013. Disponível em:<http://www.labcomifp.ubi.pt/ficheiros/20131206-201309_cristinamgomes_comunicacaocientifica.pdf>. Acesso em 15 mar. 2015.

KRAMER, B.; BOSMAN, J. 101 innovations in Scholarly Communication: the changing research workflow. 2015.2 Disponível em: $<$ https://figshare.com/articles/101_Innovations_in_Scholarly_Communication_the_Ch anging_Research_Workflow/1286826>. Acesso em: 24 nov. 2015.

Levy, P. Cibercultura. São Paulo: Editora 34,1999. Disponível em: $<$ https://www.google.pt/books?hl=pt-PT\&lr=\&id=7L29Np0d2YcC\&pgis=1>. Acesso em: 22 mar. 2015.

LIBÉRIO, L.; MALHEIRO, A.; ZAIDAN, H. Reflexões teóricas sobre o comportamento infocomunicacional de utilizadores das redes sociais na internet. Revista de Informática Aplicada, v. 7, n.1, p. 41-60, 2011. Disponível em: <http://www.ria.net.br/index.php/ria/article/view/72>. Acesso em: 24 mar. 2015.

MANCA, S.; RANIERI,M. Yes for sharing, no for teaching!": Social Media in academic practices. Internet and Higher Education, v.29, p.63-74, Apr. 2016. Disponível

em: <http://www.sciencedirect.com/science/article/pii/S1096751615300105>. Acesso em: 24 maio. 2016.

MOLINA, J. L.; MUNÕZ, J.M.; DOMENECH, M. Redes de publicaciones científicas: un análisis de la estructura de coautorías. Redes - Revista Hispana para el análisis de redes sociales, v. 1, n. 3, p. 1-15, 2002. Disponível em: <http://revistes.uab.cat/redes/article/view/v1-molina-munoz-domenech>. Acesso em: 24 maio. 2016.

MARTINS, G. A. Estudo de caso: uma estratégia de pesquisa. São Paulo: Atlas, 2006. 
MOARAIS, N. S. et al. Uso das Tecnologias da Comunicação no Ensino Superior: revisão de literatura. In: RAMOS, F.; MOREIRA, A. (Org.). Uso das Tecnologias da Comunicação no Ensino Súperior Público Português: análise, sistematização e visualização de informação nas perspectivas institucional e docente. Aveiro,

Portugal: UA Editora, 2014. p. 23-40. Disponível em: <https://ria.ua.pt/bitstream/10773/12763/1/uso\%20das\%20tecnologias\%20da\%20co municacao\%20no\%20ensino\%20superior\%20publico\%20portugues.pdf>. Acesso em: 15 mar. 2014.

NICHOLAS, David et al. New ways of building, showcasing, and measuring scholarly reputation. Learned Publishing, v. 28, n. 3, p. 169-183, 2015. Disponível em: $<$ http://www.scopus.com/inward/record.url?eid=2-s2.0-

84944054547\&partnerlD=tZOtx3y1>. Acesso em: 24 nov. 2015.

NÓVOA, A. Formação de professores e trabalho pedagógico. Lisboa, Portugal: EDUCA, 2002.

OLIVEIRA, L. A Internet como meio de partilha e divulgação da ciência: a representação da comunidade científica portuguesa. Revista Comunicação e Sociedade, número temático sobre Comunicação da Ciência, n. 6, p. 171-191, 2004.

ORDUÑA-MALEA, E.; MARTÍN-MARTÍN, A.; LÓPEZ-CÓZAR, E. D. ResearchGate como fuente de evaluación científica: desvelando sus aplicaciones bibliométricas. El profesional..., v. 25, n. 2, p. 303-310, 2016. Disponível em: <http://www.elprofesionaldelainformacion.com/contenidos/2016/mar/18.pdf>. Acesso em: 2 abr. 2016.

PINHEIRO, P. M. V., RIBEIRO, L. V. Da comunicação científica à divulgação. Transiformação, v. 20, n. 2, p. 159-169, 2005.

RECUERO, R. da C. Redes Sociais na Internet: considerações iniciais.2004. Disponível em:< http://www.bocc.ubi.pt/pag/recuero-raquel-redes-sociais-nainternet.pdf>. Acesso em: 15 nov. 2015.

SILVA, A. M. da. Terminologia essencial. In: SILVA, A. M. da. A informação: da compreensão do fenómeno e construção do objecto científico. Porto, Portugal: Edições Afrontamento, 2006.

SILVA, L. L. da; SILVA, A. M. Comportamento infocomunicacional em contextos de redes sociais online: proposta de investigação. In: INTERNATIONAL CONFERENCE ON INFORMATION SYSTEMS AND TECHNOLOGY MANAGEMENT (CONTECSI), 9., 2012. Proceedings... [s.I.: s.n.], 2012. p. 3184-3200.

THELWALL, M.; KOUSHA, K. ResearchGate: disseminating, communicating, and measuring Scholarship?Journal of the Association for Information Science and Technology, jun. 2014. Disponível em: <https://www.researchgate.net/publication/259583165_ResearchGate_Disseminating _Communicating_and_Measuring_Scholarship>. Acesso em 17 mar. 2015.

STAKE, R. A arte da investigação com estudos de caso. 5. ed. Porto Alegre, Brasil: [s.n.], 2015.

VAN-NOORDEN, R. Online collaboration: scientists and the social network. Nature, v. 512, n. $7513, \quad$ p. 126-129, 2014. Disponível em: < 
http://www.nature.com/news/online-collaboration-scientists-and-the-social-network1.15711 >. Acesso em: 16 jun. 2015.

VIEIRA, N.; VIEIRA, N. As literacias e o uso responsável da Internet. Film, v. 5, p. 193-209, 2008.

YANG, J; LESKOVEC, J. Defining and evaluating network communities based on ground-truth. Knowledge and Information Systems, 2015. Disponível em: <http://link.springer.com/article/10.1007/s10115-013-0693-z>. Acesso em: 2 abr. 2016.

YIN, R.K. Estudo de caso: planejamento e métodos. 5. ed. Porto Alegre: Bookman, 2015. 